\title{
Enhancing L2 Learners' Critical Thinking Skills Through a Connectivism-Based Intelligent Learning System
}

\author{
Jiangping $\mathrm{Chen}^{1} \& \mathrm{Jie} \mathrm{Hu}^{1}$ \\ ${ }^{1}$ School of International Studies, Zhejiang University, Hangzhou, China \\ Correspondence: Jie Hu, School of International Studies, Zhejiang University, Hangzhou, China, 310058. E-mail: \\ huj@zju.edu.cn
}

Received: June 4, 2018 Accepted: July 7, 2018 Online Published: July 28, 2018

doi:10.5539/ijel.v8n6p12 URL: https://doi.org/10.5539/ijel.v8n6p12

\begin{abstract}
The Rain Classroom, grounded in the theory of connectivism in the digital era, is a mobile-supported tool for blended learning. This tool renders synchronous and asynchronous teacher-student interactions through dual-channel teaching in and out of class. In the study, the Critical Thinking Skills Survey (CTSS) was adopted to measure the critical thinking skills (CTS) of 112 first-year undergraduates majoring in English in mainland China. A pretest-posttest non-equivalent two-group quasi-experimental design was applied to compare the CTS of those learners of English as a second language (L2) instructed under the Rain-Classroom-based intelligent learning system with those taught by the traditional lecture approach. The mixed results indicated that the intelligent learning system had a positive effect on students' overall CTS development with significant improvement in the interpretation subscale but had almost no influence on the evaluation and self-regulation subscales. The intelligent learning approach in this study is empirically meaningful in students' CTS enhancement, but further research is warranted to make this system more efficacious in facilitating L2 learners' CTS.
\end{abstract}

Keywords: connectivism, critical thinking skills, intelligent learning system, L2 learners

\section{Introduction}

\subsection{Critical Thinking (CT)}

In this increasingly technologically complex world, learning is taking place in an environment that is characterized by superabundance of information (Yang \& Wu, 2012). This environment, on one hand, offers an abundance of learning opportunities and resources on an unprecedented scale; on the other hand, there is an increased need to cultivate students' abilities to assess the authenticity and soundness of the mass of information (Yang, Newby, \& Bill, 2008). Only by enhancing students' critical thinking skills (CTS) can they effectively and creatively employ knowledge to find solutions to real-world problems (Stephenson \& Sadler-McKnight, 2016).

In terms of the working definition of $\mathrm{CT}$, the present study adopts the version proposed by the Delphi Report, which is supported by 46 experts in this field. It is described as "purposeful, self-regulatory judgment which results in interpretation, analysis, evaluation, and inference, as well as explanation of the evidential, conceptual, methodological, criteriological, or contextual considerations upon which that judgment is based" (Facione, 1990, p.2). CT is composed of cognitive skills and dispositions. The core cognitive skills are analysis, evaluation, inference, explanation, inference and self-regulation, while the dispositions encompass being open-minded, analytical, orderly and inquisitive, and truth-seeking, with good skills of interpersonal communication and strong abilities to discriminate between good and bad information (Facione, 1990). Research has consistently determined that cognitive skills can be improved in a reasonable span of time, while the improvement of dispositions involves a lengthy process (Quitadamo, Brahler, \& Crouch, 2009; Giancarlo \& Facione, 2001). Many studies have described efficient instructional strategies that promote students' CTS (Petrucco \& Ferranti, 2017; Williams \& Lahman, 2011; Greenlaw \& DeLoach, 2003).

\subsection{CTS and Technology-Integrated Instruction (TII) Strategies}

Since the 1990s, researchers have empirically corroborated the effectiveness of some novel learning approaches, as distinguished from the traditional lecturing method, in fostering students' CTS. For example, researchers have investigated collaborative learning (Nelson, 1994), self-directed learning (Kreber, 1998), concept mapping 
(Wilgis \& McConnell, 2008), problem-based learning (Pardamean, 2012), and the science writing heuristic ((Stephenson \& Sadler-McKnight, 2016). As recent decades have witnessed the rapid emergence of digital applications and multimedia tools through portable devices and less expensive software, technology has been actively integrated into teaching pedagogies and strategies of CTS development (Bunts-Anderson, 2016). In this study, technology integration is broadly termed as the use of digital tools (e.g. computers, smart phones and tablets) and social media networks (e.g., social platforms and software applications) to support teaching practices (Bunts-Anderson, 2016).

Yang (2008), and Schellens, Van Keer, De Wever and Valcke (2009) investigated the asynchronous discussion forums to upgrade their function in helping students think critically, and proposed the Socratic dialogue format and "thinking hats," respectively, as additives to the online discussion pedagogy to produce a synergy. Another study on the relationship of students' online discussion behavior and their ability to think critically was conducted by William and Lahman (2011), who determined that the frequency of students' interactions on the discussion section was correlated with the level of their thinking ability. Digital storytelling also has been favored as an entertaining means of honing learners' CTS by combining words, pictures, audio and video (Yang \& Wu, 2012). McDonald (2017), Yang (2015), Yang and Chang (2013) all reported the efficacy of digital gaming in the development of students' higher order thinking through their more concentrated participation in and increased satisfaction with the design and production of the games. A similar result was found by Kong (2014, 2015) with flipping-classroom pedagogy. Students' subject-matter knowledge, CTS, and information literacy were all demonstrated to significantly improve. The consensus is that TII strategies tend to lead to the enhancement of CTS. However, unsatisfactory results have been found in some studies. For example, the impact of long-distance interactive video tutoring on CTS was no different from that of the conventional lecture (Huff, 2000). There was no significant variance of effects between students accustomed to digital retrieval of texts and the manual methods of retrieval (Daud \& Husin, 2004). Costley (2016) found that the use of teacher-guided online discussion forums, having casual learning environments free from teachers' close supervision, did not foster students' CTS.

\subsection{CTS and TII of English as a Second Language (L2)}

Compared with other subjects, it appears more difficult for researchers and practitioners to strengthen CTS by means of L2 learning, as evidenced in Chinese English learners' "absence of critical thinking" (Huang, 1998). Investigators have obtained the same results in other countries (Sanavi \& Tarighat, 2014). This finding is largely observed because L2 learners need to use multiple cognitive processes for active participation in communication in L2, which could lead to complex cognitive overload (Baralt, 2015). However, a large body of literature has documented a fruitful yield of technology-supported instruction in facilitating L2 learners' ability to think critically without sacrificing language literacy. For instance, digital storytelling has turned out to be effective in CT-infused L2 classrooms (Sevilla-Pavón \& Nicolaou, 2017; Yang \&Wu, 2012), since students need to critically analyze and interpret the stories they listen to and create their own based on critical theorizing and reflection to persuade their audience (Malita \& Martin, 2010). This process is significantly correlated with students' interpretation and evaluation skills, two components of CTS (Yang \& Wu, 2012). Also, technology-supported environments could engage students in an authentic context for language use, such as by participating in a software-based collaborative task (Lin, Preston, Kharrufas, \& Kong, 2016), 3D printing (Roy, 2017), or playing serious games (Supuran \& Sturza, 2017). Students learn to develop analytic reasoning and externalize their thinking to others by performing tasks. Self-regulation is also required to monitor the progress of the task. Notably, computer-mediated virtual environments could alleviate physical and psychological barriers to communication. Students are more self-expressive and demonstrate better reflection skills through in-depth online activities and discussions (Habibi et al., 2018; Young, 2003). In Yang, Chuang, Li and Tseng's (2013) research, Moodle (Note 1), a virtual learning platform, was adopted for individualized instruction of English listening and speaking, as well as CTS, with positive outcomes for language proficiency and all the subscales of thinking competency. This study has several implications for CTS development. First, explicit instruction and practice of CTS (e.g., inductive reasoning involved) could help students better understand abstract skills and apply them to post-class scenarios after rational analysis and evaluation. Structured discussions using the traditional Socratic method tend to be of great help in transferring a low-order-thinking debate to a higher-order-thinking one (Yang, 2017). Also, the direct and immediate feedback from teacher and peers not only scaffolds students' development of CTS but engages them in critical inductive reasoning and self-reflection (Bunts-Anderson, 2016). 


\section{4 "Rain Classroom": A Transformative TII Strategy in Mainland China}

Siemens (2005) put forward a milestone theory of connectivism for learning that is remarkably impacted by technology, which was later elaborated by his partner Downes (2012). This era is a digital age, where the exponential growth of knowledge shrinks its half-life. Technology is performing certain of the cognitive operations by means of storing and retrieving information, which partially renders the traditional learning theories, behaviorism, cognitivism and constructivism, unable to describe and guide the knowledge-acquisition process. Siemens (2005) also claims that learning "is focused on connecting specialized information sets, and the connections that enable us to learn more are more important than our current state of knowing" (p. 4), and any alterations made to the integrated network of "people, groups, systems, nodes, entities" (p. 3) could affect the whole. This learning informs researchers of the elaborate design of every element of the platform and their reasonable linking, which is well-mirrored in the Rain Classroom in that it attaches enormous importance to students' learning behavior in every step so as to provide timely feedback and support. Additionally, learning only occurs when the knowledge in the database is connected to the right learners contextually, which prompts personalized use of the content and manner of retrieval. This theory, meanwhile, mentions the significance of information flow and social network analysis in organizing the learning model. This dual-channel teaching in the Rain Classroom helps to connect both the teacher and students into an organic learning system without the boundaries of classroom, thus contributing to high efficiency of learning.

Hughes (2005) classifies technology-integrated pedagogies into three categories depending on the role of technology in amplification, replacement or transformation. Often, instructors use technology for content delivery instead of for the employment of innovative teaching strategies. Next, instructors employ the typical lecture-type TII, where the lectures are provided on the basis of content with technological aids, such as computers, tablets, and projectors, and students mostly work individually on paper-based assignments or tests rather than collaborate with one another. However, what brings out real innovative learning opportunities is the transformative TII in which course content, classroom activities and cognitive process are reorganized, and the practices and roles of the teacher are reshaped (Yang \& Wu, 2012).

In the current research, the target intervention tool is a transformative TII strategy in mainland China (China), known as the "Rain Classroom." As a blended learning method based on massive open online courses, Rain Classroom is a mobile-learning tool developed by Tsinghua University in China in late 2016. Though a software application, it is built in WeChat, the most popular free social instant messenger application in China. The Rain Classroom integrates courseware release prior to class, real-time feedback, multi-screen virtual-classroom interaction and review after class. This tool is distinguishable by its dual-channel teaching, where the teacher and students communicate synchronously and asynchronously in and out of class, and students' whole-process learning data is generated and collected automatically by the system (Li \& Song, 2017; Wang, 2017).

\subsection{Research Objectives}

Having reviewed the research on the TII strategies' cultivation of students' CTS, especially among L2 learners, the present study aims to make its own contributions to the literature by investigating the impacts of a Rain Classroom-based intelligent learning system, which is exclusive to China, on the CTS of L2 learners with the following two research questions:

1) Is the intelligent learning system helpful to enhance L2 learners' overall CTS?

2) Does the intelligent learning system equally impact the subskills of CTS?

\section{Research Methodology}

\subsection{Research Design}

A pretest-posttest non-equivalent quasi-experimental design was adopted to measure the differences in L2 learners' CTS between the Rain Classroom (experimental group) and the traditional lecture-type TII groups (control group).

\subsection{Participants}

Participants of this study were all freshmen English majors from two universities in China. The Rain Classroom was applied to one university's English instruction to constitute the experimental group with a total of 60, among whom 13 were male $(21.67 \%)$ and 47 were female $(78.33 \%)$, while students from the lecture-type university were regarded as the control group ( $\mathrm{n}=56)$, among whom there were 10 males $(17.86 \%)$ and 46 females $(82.14 \%)$. The fact that the majority of English majors in China are usually females made it impossible to keep gender equilibrium for either group. However, the similar male-to-female ratio (1:4) for each group contributes 
to the validity of the current study. The ages of all of the students ranged from 18 to 23 years. None of the participants previously had CTS training or the intervention experience of the Rain Classroom. All of the participants were enrolled on a voluntary basis, and informed consent was obtained from them before data collection. Confidentiality was guaranteed by replacing students' names with code numbers.

\subsection{Instruments}

The Critical Thinking Skills Survey (CTSS) (Huang, 2008), designed on the basis of the California Critical Thinking Skills Test and tailored to the Chinese students, was administered to assess students' CTS. The CTSS was an objective test that consisted of 34 multiple-choice questions, with several suitable and reasonable alterations being made to the CTSS in the Chinese language version. These alterations included the modification and replacement of several questions to achieve conceptual and semantic equivalence in the Chinese context. In Huang's (2008) version, six fine-grained subskills, namely, interpretation, analysis, evaluation, inference, explanation and self-regulation, were examined (see Table 1 for their relevance to the items). One point was assigned to each correct response. A higher score was indicative of better CTS of the test-taker (Facione, Facione, Blohm, \& Giancarlo, 2002). Before the formal experiment, a pilot study was conducted among sophomore English language learners $(n=58)$ in one university. The reported $\alpha=0.925$ (Cronbach) indicated very good reliability of the test.

Table 1. Distribution of subskills of CTS in the test questions

\begin{tabular}{lll}
\hline Subskills of CTS & Number of questions & Percentage of questions (out of 34) \\
\hline Interpretation & 4 & $12 \%$ \\
Analysis & 3 & $9 \%$ \\
Evaluation & 13 & $38 \%$ \\
Inference & 10 & $34 \%$ \\
Explanation & 2 & $6 \%$ \\
Self-regulation & 2 & $6 \%$ \\
\hline
\end{tabular}

\subsection{Procedure}

The Rain Classroom was employed as the intervention tool for the experimental group, while the control group retained the lecture-type TII strategies. Two groups simultaneously commenced the same course of Comprehensive English Level One and kept the same pace of 1.5 hours per week for 12 consecutive weeks.

Before the intervention, the teacher for the experimental group was given one-day training on the intelligent learning system by the researchers and offered assistance any time over the research. The teaching and learning activities are illustrated in Table 2.

Table 2. Teaching and learning activities for the experimental group

\begin{tabular}{|c|c|c|}
\hline \multirow{2}{*}{$\begin{array}{l}\text { Before } \\
\text { Class }\end{array}$} & $\begin{array}{l}\text { - The teacher made a lesson plan in line with the curriculum } \\
\text { standards and initial understanding of the target students. } \\
\text { - } \quad \text { The teacher converted the PowerPoint slides of previewing } \\
\text { materials into a mobile courseware through Rain Classroom at the PC } \\
\text { terminal and published it to the WeChat class group. }\end{array}$ & $\begin{array}{l}\text { Students logged in to the Rain Classroom, } \\
\text { downloaded the courseware and previewed the basic } \\
\text { knowledge items. }\end{array}$ \\
\hline & $\begin{array}{l}\text { The teacher rated the students' self-learning outcomes and gave } \\
\text { feedback via text and voice on the application. The lesson plan was } \\
\text { modified considering students'strengths and weaknesses. }\end{array}$ & $\begin{array}{l}\text { - Students studied and took the quiz on the } \\
\text { courseware by themselves. } \\
\text { - } \quad \text { Students made inquiries about the confusing points } \\
\text { through the function of "report to the teacher." }\end{array}$ \\
\hline \multirow{3}{*}{ In Class } & $\begin{array}{l}\text { - The teacher started the class by clicking "class begins" on the } \\
\text { Rain Classroom, going through the PowerPoint courseware on it. } \\
\text { Meanwhile, the bulletin screen was on in case students had any } \\
\text { questions. }\end{array}$ & $\begin{array}{l}\text { - Students signed in to class and listened to the } \\
\text { teacher with the help of the PowerPoint slides on their } \\
\text { phones. } \\
\text { - Students interacted with the teacher through the } \\
\text { bulletin screen. }\end{array}$ \\
\hline & $\begin{array}{l}\text { - The teacher spent most of the time explaining difficult concepts } \\
\text { and ideas, and began discussions calling for higher order thinking. } \\
\text { - } \quad \text { The teacher answered questions in class. }\end{array}$ & $\begin{array}{l}\text { - } \quad \text { Students could press the "I don't understand" } \\
\text { button to signal to the teacher if necessary. }\end{array}$ \\
\hline & $\begin{array}{l}\text { - The teacher finished the class with a quiz for group work and } \\
\text { awarded the winners with digital money in Red Pocket or another app. }\end{array}$ & $\begin{array}{l}\text { - Students took an active part in the group work and } \\
\text { class competition. }\end{array}$ \\
\hline $\begin{array}{l}\text { After } \\
\text { Class }\end{array}$ & $\begin{array}{l}\text { - The teacher released the after-class assignment, reflected on the } \\
\text { teaching process, and interacted with students in the discussion section } \\
\text { of the Rain Classroom. }\end{array}$ & $\begin{array}{l}\text { - Students did the homework, reflected on the } \\
\text { learning process, and discussed the material with the } \\
\text { teacher and other peers in the Rain Classroom. }\end{array}$ \\
\hline
\end{tabular}


In the control group, the teacher delivered the course directly with only selective previewing and reviewing the material for the students. In class, PowerPoint slides were utilized on an overhead projector as the teacher was verbally engaged with the course content. Meanwhile, students mostly listened quietly to the teacher and took notes now and then. Group discussions were occasionally carried out in class, and students were asked to give a presentation individually as part of the assessments in the course.

Before each session, the researchers had the two teachers confer on the identical course objectives and key concepts to be addressed. After the session, they also discussed and reflected on their students' progress and learning issues.

\subsection{Data Collection}

The two researchers administered the CTSS (Huang, 2008) to two groups of students as the pretest and posttest. Students were given the recommended 45 minutes to take the test and were reminded to answer all the questions so that all the test results were guaranteed valid for further analysis.

\subsection{Data Analysis}

SPSS Statistics 22.0 was used to analyze the data. Normal distribution testing was taken first, and then independent sample $t$-tests were employed to compare the mean scores and change scores of CTS (the overall skill and six subskills) by the two groups. A confidence interval of $95 \%$ was adopted for all the analyses, which means the significant values reaching 0.05 confirmed the hypothesis that there is no significant difference between the two independent samples. The effect size was estimated by Cohen's $d$. Its magnitudes are interpreted in Table 3. Also, the cut scores for differing ability levels recommended in Huang's (2008) were utilized to more clearly reflect students' overall skills (see Table 4).

Table 3. Interpretation of the magnitudes of effect size (Kotrlik \& Williams, 2003)

\begin{tabular}{ll}
\hline The value of Cohen's $d$ & Interpretation \\
\hline 0.20 & Small effect size \\
$0.21-0.49$ & Small-to-medium effect size \\
0.50 & Medium effect size \\
$0.51-0.79$ & Medium-to-large effect size \\
0.80 or above & Large effect size \\
\hline
\end{tabular}

Table 4. Cut scores for the overall skill of CTS on the CTSS (Huang, 2008)

\begin{tabular}{llll}
\hline & Weak & Moderate & Strong \\
\hline CTSS & $0-10$ & $11-24$ & $25-34$ \\
\hline
\end{tabular}

\section{Results}

\subsection{Pretest-Posttest Scores of CTS}

No significant difference was identified between the mean scores of both overall skills $(P=0.598)$ and six subskills (all $>0.05$ ) of CTS for the two groups at the pretest (Table 5). At the posttest, however, the interpretation $(P=0.022)$ and inference $(P=0.49)$ subskills for the experimental group were statistically different from those for the control group, while their overall skills $(P=0.125)$ and the remaining four subskills $($ all $>0.05)$ were not (Table 6). In terms of the overall ability of students' CTS, the mean pretest and standard deviation scores located the students from both groups $(\mathrm{M}=16.55, \mathrm{SD}=7.69$ for the experimental group; $\mathrm{M}=15.79$, $\mathrm{SD}=7.88$ for the control group) between the weak and moderate scales. The posttest mean scores and standard deviation showed that the control group's students $(\mathrm{M}=16.43, \mathrm{SD}=7.66)$ did not change much, whereas those in the experimental group $(\mathrm{M}=18.40, \mathrm{SD}=5.89)$ all stayed in the moderate scale with some at the higher ranges of it (in reference to Table 4).

\subsection{Change Scores of CTS}

Comparison of the differences in the mean gain scores for the experimental and control groups indicated that improvement in the interpretation subskill $(P=0.002)$ was significantly greater with the intervention of the Rain Classroom, which was consistent with the value of Cohen's $d(0.61)$. The other values also signaled the small-to-medium effect size for the overall skill $(d=0.27)$ and inference subskill $(d=0.24)$ followed by the small effect size of analysis $(d=0.20)$. However, the treatment yielded almost no effects on the subskills of evaluation $(d=0.02)$ and self-regulation $(d=0.02)$ (Table 7). 
Table 5. Students' CTS on the pre-test

\begin{tabular}{|c|c|c|c|c|c|c|c|c|c|c|}
\hline \multirow{2}{*}{ CTS } & \multicolumn{2}{|c|}{$\begin{array}{l}\text { Total } \\
(\mathrm{n}=116)\end{array}$} & \multicolumn{2}{|c|}{$\begin{array}{l}\text { Experimental } \\
\text { group }(\mathrm{n}=60)\end{array}$} & \multicolumn{2}{|c|}{$\begin{array}{l}\text { Control group } \\
(\mathrm{n}=56)\end{array}$} & \multicolumn{4}{|c|}{ Independent sample $t$-test } \\
\hline & Mean & SD & Mean & SD & Mean & SD & $\begin{array}{l}\text { Mean } \\
\text { Difference }\end{array}$ & $T$ & d.f. & $P$-value \\
\hline Interpretation & 1.84 & 1.16 & 1.75 & 1.27 & 1.93 & 1.02 & -.18 & -.836 & 111.686 & .405 \\
\hline Analysis & 1.82 & .96 & 1.72 & 1.08 & 1.93 & .81 & -.21 & -1.206 & 109.032 & .230 \\
\hline Evaluation & 6.29 & 2.83 & 6.53 & 2.80 & 6.04 & 2.87 & .49 & .945 & 114 & .346 \\
\hline Inference & 4.17 & 2.67 & 4.42 & 2.81 & 3.91 & 2.52 & .51 & 1.020 & 114 & .310 \\
\hline Explanation & 1.39 & .68 & 1.40 & .69 & 1.38 & .68 & .02 & .196 & 114 & .845 \\
\hline Self-regulation & .67 & .82 & .73 & .86 & .61 & .78 & .12 & .826 & 114 & .411 \\
\hline Total score & 16.18 & 7.75 & 16.55 & 7.69 & 15.79 & 7.88 & .76 & .529 & 114 & .598 \\
\hline
\end{tabular}

Table 6. Students' CTS on the post-test

\begin{tabular}{|c|c|c|c|c|c|c|c|c|c|c|}
\hline \multirow{2}{*}{ CTS } & \multicolumn{2}{|c|}{$\begin{array}{l}\text { Total } \\
(\mathrm{n}=116)\end{array}$} & \multicolumn{2}{|c|}{$\begin{array}{l}\text { Experimental group } \\
(\mathrm{n}=60)\end{array}$} & \multicolumn{2}{|c|}{$\begin{array}{l}\text { Control group } \\
(\mathrm{n}=56)\end{array}$} & \multicolumn{4}{|c|}{ Independent sample $t$-test } \\
\hline & Mean & SD & Mean & $\mathrm{SD}$ & Mean & SD & $\begin{array}{l}\text { Mean } \\
\text { Difference }\end{array}$ & $t$ & d.f. & $P$-value \\
\hline Interpretation & 2.03 & 1.02 & 2.23 & 1.03 & 1.80 & .96 & .43 & 2.317 & 114 & $.022 *$ \\
\hline Analysis & 2.00 & .83 & 1.98 & .85 & 2.02 & .82 & -.04 & -.222 & 114 & .825 \\
\hline Evaluation & 6.65 & 3.11 & 6.87 & 3.33 & 6.41 & 2.85 & .46 & .793 & 113.18 & .429 \\
\hline Inference & 4.68 & 2.56 & 5.13 & 2.62 & 4.20 & 2.43 & .93 & 1.993 & 114 & $.049 *$ \\
\hline Explanation & 1.38 & .72 & 1.42 & .72 & 1.34 & .72 & .08 & .578 & 114 & .564 \\
\hline Self-regulation & .72 & .83 & .77 & .89 & .66 & .77 & .11 & .687 & 113.35 & .493 \\
\hline Total score & 17.45 & 6.84 & 18.40 & 5.89 & 16.43 & 7.66 & 1.97 & 1.546 & 103.20 & .125 \\
\hline
\end{tabular}

Table 7. Change scores of students' CTS

\begin{tabular}{|c|c|c|c|c|c|c|c|c|c|c|}
\hline \multirow[t]{2}{*}{ CTS } & \multicolumn{2}{|c|}{$\begin{array}{l}\text { Experimental } \\
\text { group }(\mathrm{n}=60)\end{array}$} & \multicolumn{2}{|c|}{$\begin{array}{l}\text { Control group } \\
(\mathrm{n}=56)\end{array}$} & \multicolumn{3}{|c|}{ Independent sample $t$-test } & \multirow[b]{2}{*}{$P$-value } & \multirow[b]{2}{*}{ Effect size } & \multirow[b]{2}{*}{ Cohen's $d$} \\
\hline & Mean & SD & Mean & SD & $t$ & d.f. & $\begin{array}{l}\text { Mean } \\
\text { Difference }\end{array}$ & & & \\
\hline Interpretation & .48 & 1.38 & -.13 & .33 & 3.304 & 66.305 & .61 & $.002 *$ & .61 & Medium-to-large effect size \\
\hline Analysis & .27 & 1.27 & .09 & .29 & 1.050 & 65.418 & .18 & .297 & .20 & Small effect size \\
\hline Evaluation & .33 & 4.14 & .38 & .73 & -.077 & 62.896 & -.05 & .939 & .02 & l \\
\hline Inference & .72 & 2.34 & .29 & .83 & 1.342 & 74.385 & .43 & .184 & .24 & Small-to-medium effect size \\
\hline Explanation & .02 & .79 & -.04 & .19 & .498 & 66.030 & .06 & .620 & .10 & / \\
\hline Self-regulation & .03 & 1.28 & .05 & .23 & -.121 & 63.004 & -.02 & .904 & .02 & / \\
\hline Total score & 1.85 & 6.30 & .64 & 1.39 & 1.446 & 65.154 & 1.21 & .153 & .27 & Small-to-medium effect size \\
\hline
\end{tabular}

$* P<0.05$. Change scores $=$ posttest scores-pretest scores.

\section{Discussion and Conclusions}

The preceding findings indicated that students in the Rain Classroom-based intelligent learning system had greater improvement in overall CTS than their lecture-type TII counterparts. In the treatment group, teacher-student interaction on the mobile-supported platform reduced students' reluctance or shyness to make inquiries at any moment throughout the learning process. The cultivated attitudes toward inquiry fostered students' ability to critically analyze the situation, detect the problems and discriminate the soundness of the asserted evidence (Watson \& Glaser, 1980). The teacher's immediate and direct feedback in and out of class made students compare their way of thinking with the teacher's, and derive principles from series of particular instances, thereby facilitating their self-reflection and inductive reasoning skills (Bunts-Anderson, 2016). In the frequently held discussions and group tasks, students shared the information acquired, made hypotheses for the explanation of the situation, and debated the conflicting concepts to convince others. All those could positively lead to the enhancement of CTS (Yuan, Kunaviktikul, Klunklin, \& Williams, 2008). In contrast, the relatively shortened learning time in the lecture group was thought to force the teacher mostly to prescriptively present the knowledge items to the students and ask for direct responses from them. Students were then deprived of the opportunities to analyze and decide the significance of the situation, interpret the meanings, and infer from the 
existing information to draw a conclusion. Lower-cognitive questions were not helpful to the development of students' CTS (Shen \& Yodkhumlue, 2012). Structured discussions and organized teamwork also were far from adequate. Thus, students did not have enough practice to promote their argumentation over the cognitive dissonance (Stephenson \& Sadler-McKnight, 2016).

As revealed by the statistical results, the intervention was more efficacious in promoting students' interpretation and inference than other subskills in comparison with the findings of the lecture group. As regards interpretation, the significant improvement can be largely due to students' continual interaction with the teacher and other peers. The close guidance and feedback from the teacher offered a good example to address the concepts in a coherent and cohesive manner, to which those language learners could be fairly sensitive. Therefore, the students might indirectly learn the good skill of interpreting meanings. Also, the classroom discussions and team collaboration provided a venue for students to grapple with differing ideas and render more sophisticated their skills to logically interpret and articulate their understanding, so that their viewpoints could be sensible and convincing (Yang \& Wu, 2012). Another reasonable development occurred on the inference subscale, which can proceed through inductive or deductive reasoning. Induction refers to the process of obtaining general principles from particular instances, while deduction from the general to the specific (Yuan et al., 2008). Compared with deductive reasoning, induction requires more specific information and knowledge to estimate the probability and strength of conclusions and arguments, which is a much more coherent and integrated process (Yuan et al., 2008). This directly leads to the demanding task of boosting students' overall inferential ability in a short period of time. Fortunately, the favorable environment created by the whole intelligent learning system, and the teacher's prompt feedback in particular, actively engaged students in intensive pondering over the general rules or principles to resolve various emerging problems. Students in the lecture group apparently lacked such opportunities, as mentioned before.

It is worth noticing that unlike the significant enhancement in students' CTS with technology-supported intervention conducted in many subjects in other fields, for example, nursing (Pucer, Trobec, \& Žvanut, 2014), business (Yang, 2015) and veterinary learning (Yang et al., 2008), the whole cohort of L2 learners in this study did not demonstrate salient improvement, except in the two previously examined subskills for the experimental group. This can be explained by the universal obstacles confronted by L2 learners, and also the peculiar Chinese language-learning approaches, where learners are more accustomed to the orderly memorization of the linguistic items to score high in exams. They tend to undertake more mechanical learning activities, such as paraphrasing, imitation and pattern drilling, which are apparently linked to lower-order thinking. Such long-term practices can greatly deteriorate learners' capacities to discreetly analyze and evaluate information before absorption. Other possible causes of the generally insignificant advancement of CTS for the experimental group could be a lack of explicit instruction and training in those skills, especially the weakest evaluation and self-regulation subskills, and a scarcity of deliberate efforts to integrate learning activities with elements proven to be efficient in encouraging students' CTS development, for example, think-aloud strategies and Socratic questioning for the structured discussion (Hew \& Cheung, 2014). Meanwhile, a round of after-test interviews among the treated students for comments on the learning system could be beneficial to the improvement of this system. All those provide implications for future studies. Another limitation of the current research is that the intervention period of 12 weeks may be not sufficient for evident changes to happen. Therefore, a longer or longitudinal study could help depict a more holistic picture of the progress of students' CTS.

\section{Acknowledgments}

Authors gratefully acknowledge the research support from the Research Fund for Teaching and Research Development of Liberal Arts Teachers in Zhejiang University. Authors also would like to appreciate the anonymous reviewers for valuable comments on this paper.

\section{References}

Baralt, M. (2015). Working memory capacity, cognitive complexity and L2 recasts in online language teaching. In Z. Wen, M. B. Mota, \& A. McNeill (Eds.), Working Memory in Second Language Acquisition and Processing (pp. 248-269). Bristol, England: Multilingual Matters.

Bunts-Anderson, K. (2016). Successful online learning collaboration: Peer feedback and technology integration in English composition courses. SSRN Electronic Journal. https://dx.doi.org/10.2139/ssrn.2831527

Carolyn Yang, Y., \& Chang, C. (2013). Empowering students through digital game authorship: Enhancing concentration, critical thinking, and academic achievement. Computers \& Education, 68, 334-344. https://dx.doi.org/10.1016/j.compedu.2013.05.023 
Costley, J. (2016). The effects of instructor control on critical thinking and social presence: Variations within three online asynchronous learning environments. The Journal of Educators Online, 13(1). https://dx.doi.org/10.9743/jeo.2016.1.3

Daud, N. M., \& Husin, Z. (2004). Developing critical thinking skills in computer-aided extended reading classes. $\begin{array}{lllll}\text { British Journal of Educational Technology, } & 35(4), & \text { 477-487. }\end{array}$ https://dx.doi.org/10.1111/j.0007-1013.2004.00405.x

Downes, S. (2012). Connectivism and connective knowledge: Essays on meaning and learning networks. Ottawa, Ontario: National Research Council Canada.

Facione, P. A. (1990). Critical thinking: A statement of expert consensus for purposes of educational assessment and instruction: Research findings and recommendations. Millbrae, CA: California Academic Press.

Facione, P. A., Facione, N. C., Blohm, S. W., \& Giancarlo, C. A. F. (2002). The California critical thinking skills test: CCTST. San Jose, CA: California Academic Press.

Giancarlo, C. A., \& Facione, P. A. (2001). A look across four years at the disposition toward critical thinking among undergraduate students. The Journal of General Education, 50(1), 29-55. https://dx.doi.org/10.1353/jge.2001.0004

Greenlaw, S. A., \& Deloach, S. B. (2003). Teaching critical thinking with electronic discussion. The Journal of Economic Education, 34(1), 36-52.

Habibi, A., Mukminin, A., Riyanto, Y., Prasojo, L. D., Sulistiyo, U., Sofwan, M., \& Saudagar, F. (2018). Building an online community: Student teachers' perceptions on the advantages of using social networking services in a teacher education program. Turkish Online Journal in Distance Education, 19(1), 46-61. https://dx.doi.org/10.17718/tojde.382663

Hew, K. F., \& Cheung, W. S. (2014). Improving social studies students' critical thinking. In Using Blended Learning (pp. 59-78). Singapore: Springer.

Huang, C. Y. (2008). An investigation report on the critical thinking ability of college students in China [Post-doctoral dissertation]. Retrieved from http://www.wanfangdata.com.cn/details/detail.do?_type=degree\&id=Y1711842

Huang, Y. S. (1998). Chinese thinking absence. Foreign Languages and Teaching, 7(1), 19.

Huff, M. T. (2000). A comparison study of live instruction versus interactive television for teaching MSW students critical thinking skills. Research on Social Work Practice, 10(4), 400-416. https://dx.doi.org/10.1177/104973150001000402

Hughes, J. (2005). The role of teacher knowledge and learning experiences in forming technology-integrated pedagogy. Journal of Technology and Teacher Education, 13(2), 277.

Kong, S. C. (2014). Developing information literacy and critical thinking skills through domain knowledge learning in digital classrooms: An experience of practicing flipped classroom strategy. Computers \& Education, 78, 160-173. https://dx.doi.org/10.1016/j.compedu.2014.05.009

Kong, S. C. (2015). An experience of a three-year study on the development of critical thinking skills in flipped secondary classrooms with pedagogical and technological support. Computers \& Education, 89, 16-31. https://dx.doi.org/10.1016/j.compedu.2015.08.017

Kotrlik, J. W., \& Williams, H. A. (2003). The incorporation of effect size in information technology, learning, and performance research. Information Technology, Learning, and Performance Journal, 21(1), 1.

Kreber, C. (1998). The relationships between self-directed learning, critical thinking, and psychological type, and some implications for teaching in higher education. Studies in Higher Education, 23(1), 71-86. https://dx.doi.org/10.1080/03075079812331380502

Li, X. M., \& Song, S. Q. (2017). Mobile technology affordance and its social implications: A case of "Rain Classroom". British Journal of Educational Technology, 49(2), 276-291. https://dx.doi.org/10.1111/bjet.12586

Lin, M., Preston, A., Kharrufa, A., \& Kong, Z. (2016). Making L2 learners' reasoning skills visible: The potential of computer supported collaborative learning environments. Thinking Skills and Creativity, 22, 303-322. https://dx.doi.org/10.1016/j.tsc.2016.06.004 
Malita, L., \& Martin, C. (2010). Digital storytelling as web passport to success in the $21^{\text {st }}$ century. Procedia Social and Behavioral Sciences, 2(2), 3060-3064. https://dx.doi.org/10.1016/j.sbspro.2010.03.465

McDonald, S. D. (2017). Enhanced critical thinking skills through problem-solving games in secondary schools. Interdisciplinary Journal of e-Skills and Lifelong Learning, 13, 79-96. Retrieved from http://www.informingscience.org/Publications/3711

Nelson, C. E. (1994). Critical thinking and collaborative learning. New Directions for Teaching and Learning, 59, 45-58.

Pardamean, B. (2012). Measuring change in critical thinking skills of dental students educated in a PBL curriculum. Journal of Dental Education, 76(4), 443-453.

Petrucco, C., \& Ferranti, C. (2017). Developing critical thinking in online search. Journal of e-Learning and Knowledge Society, 13(3), 35-45. https://dx.doi.org/10.20368/1971-8829/1390

Pucer, P., Trobec, I., \& Žvanut, B. (2014). An information communication technology based approach for the acquisition of critical thinking skills. Nurse Education Today, 34(6), 964-970. https://dx.doi.org/10.1016/j.nedt.2014.01.011

Quitadamo I., Brahler C., \& Crouch G. (2009). Peer led team learning: A prospective method for increasing critical thinking in undergraduate science courses. Sci. Educ, 18(1), 29-39.

Roy, D. (2017). Developing a project-based CALL environment with technical communication in an exploratory 3D printing context. International Journal of Computer-Assisted Language Learning and Teaching, 7(2), 75-101. https://dx.doi.org/10.4018/ijcallt.2017040105

Sanavi, R. V., \& Tarighat, S. (2014). Critical thinking and speaking proficiency: A mixed-method study. Theory and Practice in Language Studies, 4(1). https://dx.doi.org/10.4304/tpls.4.1.79-87

Schellens, T., Van Keer, H., De Wever, B., \& Valcke, M. (2009). Tagging thinking types in asynchronous discussion groups: Effects on critical thinking. Interactive Learning Environments, 17(1), 77-94. https://dx.doi.org/10.1080/10494820701651757

Sevilla-Pavón, A., \& Nicolaou, A. (2017). Online intercultural exchanges through digital storytelling. International Journal of Computer-Assisted Language Learning and Teaching, 7(4), 44-58. https://dx.doi.org/10.4018/ijcallt.2017100104

Shen, P., \& Yodkhumlue, B. (2012). A case study of teacher's questioning and students' critical thinking in college EFL reading classroom. International Journal of English Linguistics, 2(1), 199-206. https://dx.doi.org/10.5539/ijel.v2n1p199

Siemens, G. (2005). Connectivism: A learning theory for the digital age. International Journal of Instructional Technology and Distance Learning, 2(1), 3-10.

Stephenson, N. S., \& Sadler-McKnight, N. P. (2016). Developing critical thinking skills using the Science Writing Heuristic in the chemistry laboratory. Chemistry Education Research and Practice, 17(1), 72-79. https://dx.doi.org/10.1039/c5rp00102a

Supuran, A., \& Sturza, A. (2017). The opportunity of introducing serious games in teaching English for specific purposes. A study case on playing "simplycycle" serious game. Journal of Teaching English for Specific and Academic Purposes, 5(3), 459-466.

Wang, S. (2017). Rain Classroom facilitating commencing the era of smart teaching. Modern Educational Technology, 27, 26-32.

Watson, G., \& Glaser, E. M. (1980). Critical thinking appraisal: Manual. New York, NY: Psychological Corporation.

Wilgis, M., \& McConnell, J. (2008). Concept mapping: An educational strategy to improve graduate nurses' critical thinking skills during a hospital orientation program. The Journal of Continuing Education in Nursing, 39(3), 119-126. https://dx.doi.org/10.3928/00220124-20080301-12

Williams, L., \& Lahman, M. (2011). Online discussion, student engagement, and critical thinking. Journal of Political Science Education, 7(2), 143-162. https://dx.doi.org/10.1080/15512169.2011.564919

Yang, R. (2017). The use of questions in a synchronous intercultural online exchange project. ReCALL, 30(1), 112-130. https://dx.doi.org/10.1017/s0958344017000210 
Yang, Y. C. (2008). A catalyst for teaching critical thinking in a large university class in Taiwan: Asynchronous online discussions with the facilitation of teaching assistants. Educational Technology Research and Development, 56(3), 241-264. https://dx.doi.org/10.1007/s11423-007-9054-5

Yang, Y. C. (2015). Virtual CEOs: A blended approach to digital gaming for enhancing higher order thinking and academic achievement among vocational high school students. Computers \& Education, 81, 281-295. https://dx.doi.org/10.1016/j.compedu.2014.10.004

Yang, Y. C., \& Wu, W. I. (2012). Digital storytelling for enhancing student academic achievement, critical thinking, and learning motivation: A year-long experimental study. Computers \& Education, 59(2), 339-352. https://dx.doi.org/10.1016/j.compedu.2011.12.012

Yang, Y. C., Chuang, Y., Li, L., \& Tseng, S. (2013). A blended learning environment for individualized English listening and speaking integrating critical thinking. Computers \& Education, 63, 285-305. https://dx.doi.org/10.1016/j.compedu.2012.12.012

Yang, Y. C., Newby, T., \& Bill, R. (2008). Facilitating interactions through structured web-based bulletin boards: A quasi-experimental study on promoting learners' critical thinking skills. Computers \& Education, 50(4), 1572-1585. https://dx.doi.org/10.1016/j.compedu.2007.04.006

Yang, Y. T. C., \& Chang, C. H. (2013). Empowering students through digital game authorship: Enhancing concentration, critical thinking, and academic achievement. Computers \& Education, 68, 334-344.

Young, S. S. (2003). Integrating ICT into second language education in a vocational high school. Journal of Computer Assisted Learning, 19(4), 447-461. https://dx.doi.org/10.1046/j.0266-4909.2003.00049.x

Yuan, H., Kunaviktikul, W., Klunklin, A., \& Williams, B. A. (2008). Improvement of nursing students' critical thinking skills through problem-based learning in the People's Republic of China: A quasi-experimental study. Nursing \& Health Sciences, 10(1), 70-76. https://dx.doi.org/10.1111/j.1442-2018.2007.00373.x

\section{Note}

Note 1. Moodle (Modular Object-oriented Dynamic Learning Environment), is a free and open-source learning management system. It can be customized to create private websites with online courses and learning community for educators and trainers to achieve learning goals. For more information, please visit https://en.wikipedia.org/wiki/Moodle

\section{Copyrights}

Copyright for this article is retained by the author, with first publication rights granted to the journal.

This is an open-access article distributed under the terms and conditions of the Creative Commons Attribution license (http://creativecommons.org/licenses/by/4.0/). 